\title{
The Interrelation between Audit Quality and Managerial Reporting Choices and Its Effects on Financial Reporting Quality
}

\author{
Evelyn R. Patterson \\ Kelley School of Business \\ Indiana University \\ evpatter@iupui.edu \\ Phone: (317) 278-7843 \\ Fax: (317) 274-3312 \\ *J. Reed Smith \\ Kelley School of Business \\ Indiana University \\ jrsmith2@,iupui.edu \\ Phone: (317) 274-0867 \\ Fax: (317) 274-3312 \\ Samuel L. Tiras \\ Kelley School of Business \\ Indiana University \\ stiras@iu.edu \\ Phone: (317) 274-3420 \\ Fax: (317) 274-3312
}

November 2018

\begin{abstract}
We thank participants at the 2017 American Accounting Association Annual Meeting, the 2017 Midyear Auditing Conference, the 2015 Midwest Summer Research Conference as well as workshop participants at Indiana University, LUISS (Rome) and the Economics Institute at Zagreb for their thoughtful comments. We also thank Mark Bagnoli, John Hassell, Carol Liu and Clark Wheatley for their comments and especially Paul Newman for his advice and involvement in developing this research. Moreover, we appreciate the helpful comments provided by the associate editor, Florin Sabac, and editor-in-chief, Michael Welker, along with the two anonymous reviewers. Finally, we are grateful to the Kelley School of Business for summer grant support.

*Corresponding author
\end{abstract}




\title{
The Interrelation between Audit Quality and Managerial Reporting Choices and Its Effects on Financial Reporting Quality
}

\begin{abstract}
Two distinct lines of research have been dedicated to empirically testing how financial reporting quality (measured as the earnings response coefficient or ERC) is associated with management's choice of reporting bias and with audit quality. However, researchers have yet to consider how ERCs are affected by either the auditor's reaction to changes in the manager's reporting bias or the manager's reaction to changes in audit quality. Our study provides theoretical guidance on these interrelations, and how changes in the manager's or the auditor's incentives affect both reporting bias and audit quality. Specifically, when the manager's cost (benefit) of reporting bias increases (decreases), we find that expected bias decreases, inducing the auditor to react by reducing audit quality. Because we also find that the association between expected audit quality and ERCs is always positive, changes in managerial incentives for biased reporting lead to a positive association between ERCs and expected reporting bias. When the cost of auditing decreases or the cost of auditor liability increases, we find that expected audit quality increases, inducing the manager to react by decreasing reporting bias. In this case, changes in the costs of audit quality lead to a negative association between ERCs and expected reporting bias. Finally, we demonstrate the impact of our theoretical findings by focusing on the empirical observations documented in the extant literature on managerial ownership and accounting expertise on the audit committee. In light of our framework, we provide new interpretations of these empirical observations and new predictions for future research.
\end{abstract}




\section{The Interrelation between Audit Quality and Managerial Reporting Choices and Its Effects on Financial Reporting Quality}

\section{Introduction}

Two distinct lines of research have been dedicated to empirically testing how financial reporting quality is associated with management's choice of reporting bias and with audit quality. The extant literature has typically treated these two relationships either as independent of one another, or as interchangeable. The manager chooses an amount of reporting bias and the auditor chooses a level of audit quality. However, neither reporting bias nor audit quality affects the usefulness of financial reporting in isolation. The auditor's strategy affects the manager's reporting strategy, and conversely, the manager's reporting strategy affects the auditor's strategy, because the auditor's and manager's incentives are interdependent. DeFond and Zhang (2014) express concern about the mixed treatment of this interrelation by empirical researchers. They suggest, “...research would benefit from more conceptual guidance in disentangling the complex relation between audit quality and financial reporting quality (p. 279)." This paper provides theoretical guidance on the joint strategic effects that the manager's choice of reporting bias and the auditor's choice of audit quality have on the usefulness of financial reporting.

Consider how the Sarbanes-Oxley Act of 2002 (SOX) might affect this joint interaction. SOX instituted new audit committee requirements that boosted the independence of audit committee members and increased the financial competency of the audit committee. The extant literature provides evidence that suggests that these efforts to increase the effectiveness of audit committees reduce managerial reporting bias by increasing the cost of misreporting (for a review, see Dechow, Ge, and Schrand 2010). The presumption is that a decrease in bias would result in an increase in the usefulness of financial reporting. However, the anticipated decrease in the manager's reporting bias allows the auditor to rely more on the manager's report and to 
decrease his investment in audit procedures. This interdependence could ultimately result in a decrease in the usefulness of financial reporting.

The above example illustrates how empirical studies that examine managerial reporting bias and audit quality independently would fail to account for how these interrelations jointly affect the usefulness of financial reporting. Examples include Warfield, Wild, and Wild's (1995) study on managerial ownership and Teoh and Wong's (1993) study on big-N auditors and ERCs. Accordingly, our study constructs a model that incorporates both reporting bias and audit quality in determining the usefulness of financial reporting. In our setting, we characterize the usefulness of financial reporting as financial reporting quality, modeled as the stock market reaction to the audited financial report. Further, we define audit quality as the probability that the auditor detects the manager's financial reporting bias. ${ }^{1}$ An important attribute of our model is that we derive a linear equilibrium that yields empirically testable predictions.

To highlight the importance of auditing to financial reporting quality, we start with a benchmark setting where the probability of detecting bias is fixed and independent of the manager's report. In this setting, an exogenous increase in audit quality reduces reporting bias, but has no effect on the market's response to reported earnings (i.e., financial reporting quality). However, when we add a strategic auditor to the model who endogenously uses the manager's earnings report in choosing audit quality, financial reporting quality is affected and unambiguously increases relative to the benchmark setting. ${ }^{2}$

1 Many studies use the terms audit quality and audit effort interchangeably. Newman, Rhoades, and Smith (1996) discuss the different modeling approaches and show that they are strategically equivalent. As such, we model the auditor's choice as a choice of detection probability and refer to the auditor's strategy as "audit quality" throughout.

2 As we discuss in sections 2 and 3, the notion of exogenous versus endogenous changes in audit quality refer to whether or not the auditor observes the manager's report before choosing audit quality. However, a change in audit quality only occurs if a payoff parameter of the game changes. For the exogenous case, audit quality changes only when an auditor payoff parameter changes. For the endogenous case, audit quality changes when either an auditor's or a manager's payoff parameter changes. Consequently, if a firm changes from a non-big-N 
To model this interrelation, we consider the strategic interaction of a manager, an auditor, and market participants, all of whom are risk neutral. The manager chooses an earnings report, and the auditor chooses audit quality, after observing the manager's report. The market then sets the firm's price based on its reaction to the audited earnings report. Each player makes his strategic choice based on the inferred behaviors of the others, which depend on the common knowledge of the players' payoff incentives.

The manager's choice of reporting bias depends on both private and public information about his reporting incentives. He has two sources of private information that include: (1) true earnings; and, (2) his personal insensitivity to reporting bias. He also derives a benefit from higher reported earnings and incurs a cost for reporting bias, such as the cost of overriding internal controls or a loss of reputation. However, the impact of this cost is mitigated by his personal insensitivity to reporting bias, which is often referred to as "rationalization" in the auditing literature (see Consideration of Fraud in a Financial Statement Audit AU-C 240.11). Collectively, the manager's payoffs and private information provide him incentives to intentionally overstate earnings for his own benefit. ${ }^{3}$ Moreover, because the manager has two sources of private information, neither the market nor the auditor can "back-out" reporting bias to perfectly infer true earnings from the report. ${ }^{4}$

to a big-N auditor, expected audit quality increases in both cases due to a change in the underlying payoff parameters.

3 While the financial reporting literature often refers to this type of reporting bias as earnings management, the auditing literature considers intentional misstatements that mislead the user of the report as fraud. In our model, the intent to mislead is clear, because the earnings report affects the firm's price (AU-C 240.02). Because the Securities and Exchange Commission defines earnings management as a "material and intentional misrepresentation" of a given entity's reported operating results (see "Speech by SEC Staff: Corporate Responsibility and the Audit Committee" on March 21, 2000, by John Morrissey, Deputy Chief Accountant, U.S. Securities \& Exchange Commission), we do not distinguish between fraud and earnings management.

4 This is a well-known result in the analytical financial reporting literature. See the discussion in Fischer and Verrecchia (2000), for example. 
After observing the report, the auditor chooses the audit quality that minimizes his total conditional expected costs. He has two costs to consider: (1) the potential liability from reporting bias that goes undetected; and, (2) the direct cost of audit quality. ${ }^{5}$ Finally, the market's only objective is to set the firm's price equal to its expectation of earnings that is based on all available information, including the earnings report and the inferred audit quality strategy.

In our comparative analysis, we show how various model parameters affect three key equilibrium outcomes: (1) the market's response to reported earnings (i.e., earnings informativeness or the earnings response coefficient, ERC); (2) the manager's expected bias; and (3) the expected audit quality. Our analysis of the auditor's liability and cost parameters yields predictions that are well documented in the theoretical auditing literature. For example, we find that lowering the cost of auditing leads to higher audit quality and lower expected bias. This is a well-known result in strategic auditing papers (see Newman and Noel 1989; Schwartz 1997; Newman, Patterson and Smith 2001; among others). The consistency between the predictions of our model and the literature provides some assurance as to the construct validity of our modeling assumptions.

In contrast, we glean new insights from our analysis of the manager's incentive effects from the costs and benefits of biased reporting. As one might expect, increases in the manager's costs and decreases in the manager's benefit for reporting bias decrease expected reporting bias. However, the auditor reacts to a decrease in expected bias by reducing expected audit quality because the auditor's liability exposure for expected undetected bias decreases. Due to the

5 The auditor also receives a fee for his services, but the auditor's fee cannot depend on his choice of audit quality. All contingent fees are prohibited by both public and non-public audit standards. Thus, we assume a game structure where subsequent to setting the auditor's fee, the auditor chooses a cost-minimizing strategy. Much of the literature on strategic auditing includes this assumption. See Newman, Patterson and Smith (2001), for example. 
market's inference that audit quality decreases, the market's response to the earnings report also decreases.

A presumption in the empirical literature is that less reporting bias would result in more informative earnings. This idea is so pervasive that more recent empirical studies focus directly on the manager's decision to decrease reporting bias when the manager's cost of bias increases (for a review, see Dechow et al. 2010), without considering how the interaction between the manager's decision and audit quality might affect earnings informativeness. Bias is presumed to be negatively correlated with financial reporting quality. However, when we include endogenous audit quality in the analysis, this may no longer be the case, potentially opening new lines of research. For example, what level of audit quality is required in order to maintain the same level of financial reporting quality when managerial costs of bias increase?

Our comparative analysis also shows that expected bias increases when the manager benefits more from higher reported earnings, as with compensation plans based on reported earnings. At the same time, the market's response to the earnings report and expected audit quality increase. When management compensation is more dependent on the earnings report, the auditor increases audit quality in response to the manager's greater incentive to over-report earnings. The market views these changes as making the earnings report more informative. Dechow et al.'s (2010) review of the extant literature finds that the empirical evidence is mixed concerning the effects of managerial compensation on earnings informativeness. Our study suggests that empirical observations of a positive association between compensation plans and earnings informativeness may be due to the auditor increasing audit quality in response to the expected increase in reporting bias, a link that is empirically testable. 
Unlike expected bias, expected audit quality is always positively associated with financial reporting quality, where any parameter change that induces an increase in expected audit quality also induces an increase in financial reporting quality. This result links to the empirical literature and is particularly important, because as DeFond and Zhang (2014) note, "audit quality improves financial reporting quality by increasing the credibility of the financial reports (p.276)." In our framework, where financial reporting quality reflects the usefulness of the financial reports, increases in the credibility of the financial reports result directly from increases in audit quality, and thus increase the market's reaction to the financial report.

Our paper incorporates aspects of two streams of research that study financial reporting and strategic auditing. Similar to the strategic audit literature, we include a manager who has incentives for intentional misreporting and an independent auditor who wishes to minimize his expected costs associated with non-detection of an intentional misstatement and the costs of auditing. Similar to the theoretical financial reporting literature, we focus on deriving a linear pricing function that reflects the manager's incentives and, in our case, the auditor's incentives. This linearity allows us to study the impact of the earnings report on the market price of the firm in a way that yields empirically testable predictions.

Papers in the strategic audit literature that study the impact of the external auditor on the market price of the client firm include Chan and Pae (1998), Newman, Patterson, and Smith (2005), and Beyer and Sridhar (2006). However, these studies provide no basis for evaluating the importance of the earnings report on the market price of the firm because their analyses do not include an earnings report by the manager. Consequently, they are silent regarding financial reporting quality. Our paper is notable because we provide predictions on the association between the earnings report and the market's reaction to the report, given the addition of a 
strategic external auditor. Other models, such as Newman and Noel (1989), Shibano (1990), Hillegeist (1999), and Laux and Newman (2010) either avoid the reporting issue altogether or assume a binary report.

Our paper also has elements similar to studies found in the theoretical financial accounting literature, such as Fischer and Verrecchia (2000), Dye and Sridhar (2004) and Caskey, Nagar, and Petacchi (2010). Both Fischer and Verrecchia (2000) and Dye and Sridhar (2004) develop rational expectations equilibria of market pricing in which the manager has private information about earnings and his own payoff-type. Fischer and Verrecchia (2000) incorporate the manager's private information about his payoff-type by including a multiplicative random variable on the manager's benefit from firm pricing. Alternatively, Dye and Sridhar (2004) include an additive random variable in the manager's cost function. Because we are focused on deriving a linear equilibrium, we follow the Dye and Sridhar (2004) approach by including an additive random variable in the manager's cost function. Caskey et al. (2010) add an audit committee as a strategic player to the Fischer and Verrecchia (2000) model, which functions as an additional layer of firm management in their study. Their model does not include an external strategic auditor that provides endogenous audit quality.

Finally, in response to DeFond and Zhang's (2014) call for theoretical guidance for empirical research, our model ties to key points that DeFond and Zhang (2014) emphasize in their review of the empirical auditing literature. First, DeFond and Zhang (2014) argue that contrary to the empirical treatment of audit quality as binary, audit quality is a continuous function. We model audit quality in this fashion. Second, DeFond and Zhang (2014) also review many definitions of audit quality, but point out that a fundamental attribute of audit quality is that it improves financial reporting quality. Our definition of audit quality and the 
results of our model are consistent with this attribute. Next, the type of auditing we model is auditing for reporting bias, which DeFond and Zhang (2014) argue is the underpinning of the extant empirical literature. Finally, our linear equilibrium provides a basis for applying an ordinary least squares approach, as is typically found in the empirical literature. Together, the underlying assumptions and modeling choices of our paper answer DeFond and Zhang's (2014) call for theoretical guidance for future empirical auditing research.

The remainder of this paper is organized as follows. In section 2, we present a benchmark model in which audit quality is not strategic but exogenously fixed. We add a strategic auditor in section 3 to obtain endogenous audit quality, provide a comparative analysis in section 4, and discuss the empirical implications of our analysis in section 5. Finally, in section 6 , we provide concluding remarks.

\section{Benchmark model with exogenously fixed audit quality}

We begin by considering a benchmark setting that describes the strategic interaction between a manager and the market with exogenously fixed audit quality. Fixed audit quality implies that the probability of detecting reporting bias is independent of the report. ${ }^{6}$ Our benchmark setting provides a contrast to highlight how the addition of a strategic auditor affects the manager's reporting decision and the market's assessment of the report.

In our benchmark model, the manager privately observes the firm's earnings $\pi$ and then issues a report $r$ on earnings, where $\pi$ is normally distributed with mean $\mu_{\pi}>0$ and variance $\sigma_{\pi}^{2}$. The probability that the auditor detects bias is $\delta \in[0,1]$. The market then determines the firm's stock price based on the manager's report and whether or not bias is detected.

6 The benchmark setting might be descriptive of instances where specialized audits are consistent with "fixed" auditing, such as forensic and government mandated audits. 
With no detection (ND), the market prices the firm at the expected value of earnings $\pi$

given $r$ :

$$
P_{N D}=E(\pi \mid r)
$$

The market price with detection (D) is then equal to $P_{D}=\pi$, because detection reveals the extent of bias. ${ }^{7}$

When bias goes undetected, with probability $(1-\delta)$, the manager obtains a benefit proportionate to the market price of equity $\tau P_{N D}$, where $\tau>0$ is the manager's benefit payoff parameter. The parameter $\tau$ depends on the manager's equity holdings in the firm or a marketbased compensation plan. Because holdings and compensation plans are common knowledge, $\tau$ is also common knowledge. If bias is detected, the manager's expected benefit is $\tau \pi$. Thus the manager's total expected benefit is $\tau E(\pi \mid r)(1-\delta)+\tau \pi \delta$.

The manager also incurs a penalty of $(q / 2)(r-\pi-\varepsilon)^{2}$ where $q>0$ is a cost payoff parameter and $\varepsilon$ represents the manager's "type," which is privately known to the manager and distributed normally with mean $\mu_{\varepsilon}>0$ and variance $\sigma_{\varepsilon}^{2} \cdot{ }^{8}$ The cost parameter $q$ is common knowledge and determines the total cost based on the amount of bias. The manager's type $\varepsilon$ reflects the manager's insensitivity to the penalty from bias. As $\varepsilon$ increases, the penalty for bias is less effective in deterring bias. ${ }^{9}$

7 We assume that when bias is detected, it is observable by the market. In addition to being reasonable given the strategic nature of our setting, this assumption provides simplicity and allows us to maintain a linear equilibrium.

8 Fischer and Verrecchia (2000) include the manager's private information about his type as the multiplier on market price, but assume that the manager's misreporting penalty is known. In the model with a strategic external auditor that we present in section 3, no linear pricing equilibrium exists with the Fischer and Verrecchia (2000) structure. See additional details in the Online Appendix. Our expression for misreporting cost is consistent with Dye and Shridhar (2004), who also model the manager's cost of biasing the report as uncertain.

9 To facilitate our analysis and because $\pi$ and $\varepsilon$ are continuous normal random variables, we assume, that (1) $\mu_{\pi}>0$, (2) $0<\sigma_{\varepsilon}<\mu_{\varepsilon} / 3$, and (3) $\left.\sigma_{\pi}<\beta k\left(q \mu_{\varepsilon}+\beta \tau\right)\right) /(3(1-\beta)(k q+L \beta \tau))$ as well as 
One interpretation of the manager's type is that it reflects the manager's disposition for dishonest behavior. Audit standard AU-C 240.A1, Consideration of Fraud in a Financial Statement Audit, refers to this as rationalization as follows:

Some individuals possess an attitude, character, or set of ethical values that allow them knowingly and intentionally to commit a dishonest act.

The random variable $\varepsilon$ captures this idea, while the observable parameter $q$ measures the overall strength of the manager's misreporting cost associated with overriding internal control, legal exposure, and loss of reputation.

The manager's total expected payoff, therefore, is equal to the following.

$$
M=\tau E(\pi \mid r)(1-\delta)+\tau \pi \delta-\frac{q}{2}(r-\pi-\varepsilon)^{2}
$$

Lemma 1 provides the equilibrium strategies for the manager and the market based on expressions (1) and (2). For expositional simplicity, we define $\gamma=\sigma_{\pi}^{2} /\left(\sigma_{\pi}^{2}+\sigma_{\varepsilon}^{2}\right)$ such that an increase in $\gamma$ corresponds to an increase in the relative informativeness about the manager's type. In addition, we define $E(r)$ as expected reported earnings and $E($ bias $)=E(r)-\mu_{\pi}$.

LEMMA 1. The equilibrium strategies for exogenously fixed audit quality $\delta$ are as follows.

$$
\begin{aligned}
& \text { Manager: } \quad r=b_{m} \pi+c_{m} \varepsilon+a_{m} \text { with } b_{m}=1, c_{m}=1, a_{m}=\frac{\gamma \tau(1-\delta)}{q} \text { and } 0 \leq \delta \leq 1 . \\
& \text { Market: } \quad P_{N D}=\beta r+\alpha \text { and } P_{D}=\pi
\end{aligned}
$$

(4) $k / L>\mu_{\varepsilon}>\operatorname{Max}\left[0,\left(-L \tau \beta^{2}-k^{2} q \beta^{\prime}[k] / L q\left(\beta-k \beta^{\prime}[k]\right)\right)\right]$. The first three assumptions ensure that the manager overstates with high probability. The fourth is associated with the requirement that audit quality lies between 0 and 1. However, we can also show that our equilibrium holds for extreme values of $\pi$ and $\varepsilon$ that occur with low probability. See the discussion and proof of these issues in the Online Appendix. Similar assumptions associated with the normal distribution are also found in previous studies, such as Patterson and Smith (2003). 


$$
\begin{aligned}
& \text { where } \beta=\frac{\gamma b_{m}}{\gamma b_{m}^{2}+(1-\gamma) c_{m}^{2}}=\gamma \text { and } \\
& \alpha=(1-\beta) \mu_{\pi}-\beta E(\text { bias })=(1-\gamma) \mu_{\pi}-\gamma\left(\mu_{\varepsilon}+\frac{\tau \gamma(1-\delta)}{q}\right) .
\end{aligned}
$$

(All proofs are in the appendix.)

The equilibrium in Lemma 1 holds whether or not audit quality is greater than zero. If audit quality is zero $(\delta=0)$, bias is never detected and the market price simply equals $P_{N D}$. Furthermore, Lemma 1 implies that market price, with no detection, can also be expressed as $\beta$ times unexpected reported earnings plus expected earnings.

$$
P_{N D}=\beta(r-E(r))+\mu_{\pi}
$$

Because $\beta$ represents the market's response to unexpected reported earnings (i.e., ERC), $\beta$ represents the market's assessment of financial reporting quality. In this case, $\beta=\gamma$ because the manager's report is characterized by $b_{m}=c_{m}=1$ and the covariance of $r$ with earnings simplifies to $\gamma=\sigma_{\pi}^{2} /\left(\sigma_{\pi}^{2}+\sigma_{\varepsilon}^{2}\right)$.

In this setting, reporting bias $r-\pi$ is equal to $\varepsilon+a_{m}=\varepsilon+\gamma \tau(1-\delta) / q$, which is positive with high probability because we assume that $\mu_{\varepsilon}>0$ is sufficiently large and that $\sigma_{\varepsilon}^{2}$ is sufficiently small (see footnote 9). Reporting bias decreases as the exogenously fixed audit quality $\delta$ increases or the manager's cost parameter $q$ increases (or benefit parameter $\tau$ decreases). Reporting bias increases as more is known about the manager's type relative to earnings ( $\gamma$ increases), or the manager type $\varepsilon$ increases. However, only $\gamma$ and $\varepsilon$ affect the market price, while neither of the manager's payoff parameters $q$ or $\tau$, nor the fixed audit 
quality $\delta$, affect the market price. This is true because $a_{m}$ is an additive component in both $r$ and $E(r)$ and thus cancels out in the computation of unexpected reported earnings $r-E(r)$.

\section{Model with endogenous audit quality}

In this section, we add a strategic auditor who chooses the probability of detecting bias $\delta(r) \in[0,1]$ after observing reported earnings $r .{ }^{10}$ As a result, the amount and effects of auditing become endogenous to the model. ${ }^{11}$ The time line below depicts the sequence of moves.

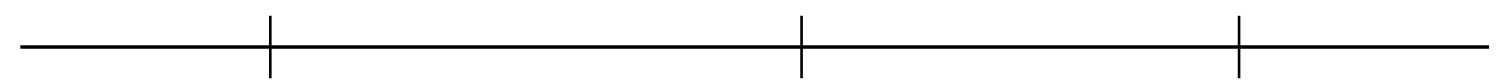

Based on his type $\varepsilon$ and after his observation of actual earnings $\pi$, the manager chooses report $r$. In choosing $r$, the manager anticipates the strategic choices that the auditor and market would make based on their reaction to $r$.
The auditor observes $r$ and then chooses audit quality $\delta$.
If no bias is detected, the market prices the firm at

$$
P_{N D}=E[\pi \mid r]
$$

otherwise, the firm is priced at

$$
P_{D}=\pi \text {. }
$$

We assume that the auditor's fee is fixed prior to the auditor choosing $\delta$. Thus, the auditor's choice of $\delta$ minimizes his expected costs. This characterization of the auditor's expected payoff avoids contingent fees that are prohibited by the auditing standards.

In focusing on overstatements, the auditor's liability penalty is $L(r-\pi)$ and his conditional expected liability penalty is $L(r-E(\pi \mid r))$ whenever bias goes undetected. The legal liability payoff parameter $L$ reflects the auditor's litigation or regulatory environment. This is the typical litigation penalty found in the strategic audit literature (for example, see Chan and

10 The actual sequence of events is that the auditor chooses the extent of audit procedures, which then determines audit quality. For simplicity, we represent audit quality as the single choice of $\delta$.

11 As noted previously, audit quality equals $\delta$ and reporting bias equals $r-\pi$. However, when audit quality is endogenous, both audit quality and reporting bias depend on realizations of the random variables $\pi$ and $\varepsilon$. Consequently we use expected audit quality and expected reporting bias that provide overall measures of these two strategic variables in our comparative analysis in section 4 . 
Pae 1998; Patterson and Noel 2003; among others). In financial reporting, the auditing standards and the auditing profession are most concerned with undetected overstatements, where understatements are typically associated with a zero litigation penalty $(L=0)$. In addition, the auditor incurs a direct cost of $(k / 2) \delta^{2}$ for choosing audit quality $\delta$ where $k$ is a cost parameter. For example, a larger $k$ could be due to a more complex client firm environment, a smaller audit firm, or less familiarity with the client's industry. As a result, the auditor's total expected costs are as follows.

$$
A=(1-\delta) L(r-E(\pi \mid r))+\frac{k}{2} \delta^{2}
$$

The auditor chooses audit quality $\delta$ by minimizing his expected costs in expression (4). In contrast to the benchmark setting of exogenously fixed audit quality, the addition of a strategic auditor provides the basis for an endogenous choice of audit quality $\delta$ that depends on reported earnings $r$. The manager's expected payoff shown in expression (2) remains the same, except that $\delta$ is now determined from the auditor's expected payoff in (4). ${ }^{12}$

Based on the expected payoffs defined in (1), (2) and (4), the equilibrium to the game with a strategic external auditor is found in Proposition 1.

PROPOSITION 1. The equilibrium strategies for the manager, the auditor and the market are as follows.

Manager: $r=b_{m} \pi+c_{m} \varepsilon+a_{m}$.

Auditor: $\delta=b_{A} r+a_{A}$.

12 In order to obtain linear equilibria, and because it does not interfere with the basic auditor and manager tensions, we do not assume an explicit penalty for the manager when the auditor detects bias. The total expected benefit from bias $\tau((1-\delta) E(\pi \mid r)+\delta \pi)$ provides the strategic tension in our model and is consistent with previous strategic audit studies such as Newman et al. (1996) and Hillegeist (1999). 
Market: $P_{N D}=\beta r+\alpha$ given no detection of bias and $P_{D}=\pi$ given detection

$$
\begin{gathered}
\text { where } b_{m}=\frac{q+b_{A} \tau}{q+2 b_{A} \beta \tau}, c_{m}=\frac{q}{q+2 b_{A} \beta \tau}, a_{m}=\frac{\left(a_{A}(1-2 \beta)+\beta\right) \tau}{q+2 b_{A} \beta \tau}, \\
b_{A}=\frac{L}{k}\left(1-\frac{q \gamma\left(q+b_{A} \tau\right)}{q^{2}-b_{A}^{2} \gamma \tau^{2}}\right), a_{A}=\frac{L}{k}\left(-(1-\beta) \mu_{\pi}+\beta \frac{k\left(q \mu_{\varepsilon}+\beta \tau\right)}{k q+L \beta \tau}\right), \\
\beta=\frac{q \gamma\left(q+b_{A} \tau\right)}{q^{2}-b_{A}^{2} \gamma \tau^{2}} \text { and } \alpha=(1-\beta) \mu_{\pi}-\beta \frac{k\left(q \mu_{\varepsilon}+\beta \tau\right)}{k q+L \beta \tau}
\end{gathered}
$$

In Proposition $1, b_{A}$ represents the responsiveness of the auditor to the manager's reported earnings $r$. While $b_{A}=(L / k)\left(1-\left(q \gamma\left(q+b_{A} \tau\right) /\left(q^{2}-b_{A}^{2} \gamma \tau^{2}\right)\right)\right)$ is a cubic equation with three roots, we focus on the unique solution in which $b_{A}$ and $\beta$ are positive, real numbers. ${ }^{13}$ We also derive, as part of the proof to Proposition 1, the equilibrium values of expected bias $E($ bias $)$ and expected audit quality $E(\delta)$.

COROllary 1. Based on Proposition 1:

$$
E(\text { bias })=\frac{k\left(q \mu_{\varepsilon}+\beta \tau\right)}{k q+L \beta \tau} \text { and } E(\delta)=\frac{L\left(q \mu_{\varepsilon}+\beta \tau\right)}{k q+L \beta \tau}
$$

Unlike the model in section 2 that exogenously fixes audit quality, the market price now depends on the manager's payoff parameters $\tau$ and $q$ as well as the auditor's payoff parameters $k$ and $L$. Despite the elimination of $a_{m}$ in unexpected reported earnings $r-E(r)$, the players'

13 Professional standards suggest that the risk of overstatement increases as reported earnings increases and $b_{A}<0$ would be counter to this presumption. In addition, these expressions could be stated in closed form, but their complexity would add more confusion than intuition. Thus, for simplicity, we express the equilibrium implicitly. We also perform reasonableness analyses on the equilibrium values of $b_{A}, b_{m}$ and $c_{m}$, which we include in the Online Appendix. 
payoff parameters affect the report $r$ and $\beta$ through $b_{m}$ and $c_{m}$ solely due to the fact that $b_{A}>0$. As a result, $\beta$ unambiguously increases relative to the benchmark setting (see Figure 1).

(Place Figure 1 about here)

COROLLARY 2. Financial reporting quality is greater with a strategic auditor $\left(b_{A}>0\right)$ than with fixed auditing $\left(b_{A}=0\right)$.

With a strategic auditor, based on Proposition 1, we can rewrite $\beta$ as

$$
\beta=\frac{\gamma}{\gamma+\left(\frac{q}{q+b_{A} \tau}\right)^{2}(1-\gamma)} \frac{1}{b_{m}}
$$

where $q /\left(q+b_{A} \tau\right)=c_{m} / b_{m}$.

Furthermore, based on expression (3), the market price $P_{N D}$ is equal to

$$
P_{N D}=\frac{\gamma}{\gamma+\left(\frac{q}{q+b_{A} \tau}\right)^{2}(1-\gamma)}\left(\pi-\mu_{\pi}+\frac{q}{q+b_{A} \tau}\left(\varepsilon-\mu_{\varepsilon}\right)\right)+\mu_{\pi} .
$$

Expression (6) illustrates the importance of the ratio $\left(q /\left(q+b_{A} \tau\right)\right)$ on the market price, $P_{N D}$.

Because $b_{A}$ depends on $q, \tau, k$, and $L$ (see Proposition 1), this ratio also depends on both the manager's and auditor's payoff parameters. While the manager's report is affected through individual changes in $b_{m}, c_{m}$ and $a_{m}$ for a change in any one of these parameters, only the change in $c_{m} / b_{m}$ affects a change in $P_{N D}$. Intuitively, as this ratio increases, the manager's report is less predictive of earnings, which in turn decreases the report's informativeness. In general, $\beta$ reflects the relative weightings that the manager puts on $\varepsilon$ and $\pi$ in his reporting strategy. Furthermore, Proposition 1 shows that the choice of audit quality can be expressed as 


$$
\delta=b_{A}(r-E(r))+E(\delta)=\frac{L}{k}((1-\beta)(r-E(r))+E(\text { bias }))
$$

where $E(\delta)=(L / k) E($ bias $)$. Expression (7) illustrates that the auditor's choice of $\delta$ is driven by two factors: the expected bias $E($ bias $)$ and the difference between the observed report and the anticipated report $(r-E(r))$, which is unexpected earnings.

The use of $(r-E(r))$ in determining audit quality is analogous to the use of analytical procedures in determining the auditing plan. PCAOB AS 1105.21, Audit Evidence, states:

Analytical procedures consist of evaluations of financial information made by a study of plausible relationships among both financial and nonfinancial data. Analytical procedures also encompass the investigation of significant differences from expected amounts. (Emphasis added)

The auditor forms his reporting expectations based on prior audits and current economic conditions. Moreover, PCAOB AS 2110.46, Identifying and Assessing Risks of Material Misstatement, states that the auditor "should perform analytical procedures" in assessing the risk of material misstatements, which the auditor uses in choosing audit quality $\delta$. As $b_{A}$ increases, the auditor puts more weight on unexpected reported earnings in choosing audit quality.

The strategies presented in Proposition 1 form the basis for our comparative analysis presented in section 4 and our empirical predictions in section 5. We examine how the key equilibrium values of financial statement quality, $\beta$, expected bias $E($ bias $)$ and expected audit quality $E(\delta)$, change with respect to a change in each of the model parameters (see Corollary 1 and Proposition 1 for derivations of these key values). 


\section{Comparative analysis}

In this section, we first examine the effects of changes in the auditor's incentives for auditing (the direct cost of audit quality $k$ and the cost of auditor liability $L$ ) along with the manager's incentives for bias (the cost of bias $q$ and the benefit from bias $\tau$ ). Subsequently, we examine the effects of changes in distributional parameters: the expected manager type $\mu_{\varepsilon}$, expected earnings $\mu_{\pi}$, the variance of manager type $\sigma_{\varepsilon}^{2}$, and the variance of earnings $\sigma_{\pi}^{2}$. We provide the results of payoff and distributional parameters in separate Propositions because the discussion of related empirical implications discussed in section 5 focuses only on the payoff parameters. Payoff parameters tend to be firm specific whereas distributional parameters tend to be associated with the general environment.

The comparative analysis related to the payoff parameters is partly driven by the direct and indirect effects that these payoffs have on the auditor's and the manager's strategic choices. Changes in the auditor's liability $\operatorname{cost} L$ and cost parameter $k$ affect audit quality directly. The auditor chooses a higher expected audit quality for an increase in $L$, but a lower expected audit quality for an increase in $k$ (direct effect). The manager reacts (indirect effect) to these changes in expected audit quality by decreasing and increasing expected bias, respectively.

Similarly, the manager decreases expected bias as the cost of bias $q$ increases and increases expected bias as the manager's benefit from bias $\tau$ increases (direct effect). The auditor reacts (indirect effect) to a lower (higher) expected bias by choosing a lower (higher) expected audit quality.

We present the comparative results for the payoff parameters in Proposition 2. 
PROPOSITION 2. The following table shows the effects of changes in the auditor and manager payoff parameters on the key equilibrium values.

\begin{tabular}{|c|c|c|c|}
\hline \multirow[b]{2}{*}{$\begin{array}{c}\text { Increase in } \\
\text { payoff parameter }\end{array}$} & \multicolumn{3}{|c|}{ Change in key equilibrium values } \\
\hline & $\begin{array}{c}\text { Expected bias } \\
E(\text { bias })\end{array}$ & $\begin{array}{l}\text { Expected audit } \\
\text { quality } E(\delta)\end{array}$ & $\begin{array}{l}\text { Financial reporting } \\
\text { quality (ERC) } \beta\end{array}$ \\
\hline Cost of audit quality $k$ & + & - & - \\
\hline $\begin{array}{l}\text { Cost of auditor } \\
\text { liability } L\end{array}$ & - & + & + \\
\hline $\begin{array}{l}\text { Cost of managerial } \\
\text { bias } q\end{array}$ & - & - & - \\
\hline $\begin{array}{l}\text { The benefit from } \\
\text { managerial bias } \tau\end{array}$ & + & + & + \\
\hline
\end{tabular}

Overall, changes in $k$ and $L$ affect $E$ (bias) in the opposite direction from their effects on $E(\delta)$, whereas changes in $q$ and $\tau$ affect $E($ bias $)$ in the same direction as their effects on $E(\delta)$. These directional differences result from the differences in the direct and indirect effects, as discussed above. These interactive results are similar to those found in previous studies, such as Hansen (1993), Radhakrishnan (1999), Patterson and Smith (2007, 2016), among others.

Changes in the parameters $k, L, q$, and $\tau$ affect $\beta$ in the same direction as they affect $E(\delta)$. Increases in $E(\delta)$ do not cause increases in $\beta$ but they are positively associated. This characteristic is consistent with the assertion of DeFond and Zhang (2014) that higher audit quality is characterized by "greater assurance of high financial reporting quality." As a result, the association between $E$ (bias) and $\beta$ is identical to the association between $E$ (bias) and $E(\delta)$ 
As noted in our discussion following Corollary 2, the ratio $q /\left(q+b_{A} \tau\right)=c_{m} / b_{m}$ represents the relative weighting of managerial-type and earnings in the manager's reporting function. It is the primary driver for determining the informativenes of reported earnings $(\beta)$ for any change in the payoff parameters. In particular, increases in $q$ decrease $E($ bias $)$, but the increase in $q$ also increases the relative weighting on manager-type $\varepsilon$ in the manager's reporting function. As a result, the manager's report is less predictive of earnings, which in turn decreases the report's informativeness. Consequently, financial reporting quality $\beta$ decreases along with $E(\delta)$. This is in contrast to Fischer and Verrecchia (2000) who find that increases in $q$ decrease $E$ (bias), as we do, but that the decrease in $E$ (bias) results in an increase in $\beta$.

Alternatively, when auditor liability $L$ increases or the cost of audit quality $k$ decreases, the manager weighs earnings more in his reporting function. As a result, financial reporting quality $\beta$ increases along with a decrease in $E($ bias $)$ and an increase in $E(\delta)$. This maintains the positive association between $E(\delta)$ and $\beta$, but $E($ bias $)$ and $\beta$ are negatively associated as in Fischer and Verrecchia (2000). However, unlike Fischer and Verrecchia (2000) this negative association is only achieved in our setting with the addition of a strategic auditor that results in endogenous audit quality.

Next, we consider the effects of changes in the distributional parameters of our two random variables, manager-type $\varepsilon \sim N\left[\mu_{\varepsilon}, \sigma_{\varepsilon}^{2}\right]$ and earnings $\pi \sim N\left[\mu_{\pi}, \sigma_{\pi}^{2}\right]$, on the key equilibrium values of $E($ bias $), E(\delta)$, and $\beta$. Based on the characterizations of $E($ bias $)$, $E(\delta)$, and $\beta$ in Proposition 1 and Corollary 1 , clearly changes in expected earnings $\mu_{\pi}$ do not affect these key equilibrium values. In addition, changes in the expected managerial-type $\mu_{\varepsilon}$ 
impact both expected bias $E($ bias $)$ and expected audit quality $E(\delta)$ where both of these equilibrium values increase in $\mu_{\varepsilon}$. As the manager's expected insensitivity to penalties $\mu_{\varepsilon}$ increases, expected audit quality and expected reporting bias increase.

Alternatively, uncertainty about managerial-type and earnings, $\sigma_{\varepsilon}^{2}$ and $\sigma_{\pi}^{2}$, impact all of the key equilibrium values only through changes in $\gamma=\sigma_{\pi}^{2} /\left(\sigma_{\pi}^{2}+\sigma_{\varepsilon}^{2}\right)$, where $\gamma$ corresponds to the relative informativeness of the manager's payoff-type. This is summarized in Proposition 3.

Proposition 3. An increase in $\gamma$ results in an increase in $\beta, E(\delta)$, and $E($ bias $)$.

An increase in $\gamma$ is due to either a decrease in $\sigma_{\varepsilon}^{2}$ or an increase in $\sigma_{\pi}^{2}$. As $\gamma$ increases, the market and auditor become relatively more informed about the manager's payoff-type. The effects of an increase in $\gamma$ are similar to those associated with the manager's benefit payoff parameter $\tau .{ }^{14}$ Financial reporting quality $\beta$ increases at the same time that expected bias and expected audit quality increase. These effects on $\beta$ and expected bias are present whether or not the setting includes a strategic auditor (see section 2 and Fischer and Verrecchia 2000). With a higher $\gamma$, the variation in reported earnings is more likely due to a variation in actual earnings rather than variations in the manager's insensitivity to the misreporting cost. Furthermore, despite reported earnings being more predictive of actual earnings, expected bias also increases.

\section{Empirical implications}

This section focuses on the interpretations of the empirical evidence related to how reporting bias and audit quality affect financial reporting quality in light of our findings. As

14 As discussed previously, an increase in $\tau$ results in a relatively smaller weight on manager-type in the manager's reporting function, decreasing the variability of the manager's report. Thus, financial reporting quality increases. However, this type of change is related to specific payoffs rather than the reporting environment, as is the case for an increase in $\gamma$. 
DeFond and Zhang (2014) point out, the empirical literature has defined financial reporting quality across many dimensions, but we specifically address financial reporting quality in terms of earnings informativeness or earnings response coefficients (ERCs). Early ERC research provides extensive empirical evidence that ERCs vary significantly with audit quality and with managerial incentives that affect reporting bias. Our findings provide new insights into these observed associations.

The empirical literature to date has not considered how the auditor's or manager's reactions to changes in reporting bias or audit quality, respectively, may affect these associations. In Proposition 2, we demonstrate that as the cost of reporting bias $q$ increases or the benefit from reporting bias $\tau$ decreases, expected bias decreases. The auditor reacts to a decrease in expected bias by reducing audit quality. Following the key finding of Proposition 2 that the association between ERCs and expected audit quality is always positive, an increase in $q$ or a decrease in $\tau$ leads to a positive association between ERCs and expected reporting bias.

In contrast, Proposition 2 shows that as the cost of auditing $k$ decreases or the cost of auditor liability $L$ increases, expected audit quality increases. The manager reacts to the increase in expected audit quality by decreasing reporting bias. Because the association between ERCs and expected audit quality is always positive, a decrease in $k$ or increase in $L$ leads to a negative association between ERCs and expected reporting bias. We depict these relations in Figure 2.

(Place Figure 2 about here)

To illustrate the implications of Proposition 2 on the interpretation of the empirical findings found in previous research, consider, for example, Warfield et al. (1995) who study the effects of managerial ownership on ERCs. They find a positive association between managerial ownership and ERCs. 
Within the framework of our model, the positive association that Warfield et al. (1995) document follows from the auditor's reaction to the effects of higher managerial ownership on expected reporting bias. Higher managerial ownership is expected to result in a higher benefit (higher $\tau$ ) and possibly a lower cost (lower $q$ ) to the manager for reporting biasedly. ${ }^{15}$ This is reflected in PCAOB Auditing Standard 2401.85 that identifies a "significant financial interest by the manager in the entity" as a fraud risk factor. Thus consistent with the PCAOB, higher managerial ownership in our framework would induce increased managerial reporting bias and increased audit quality, resulting in the observed positive association between managerial ownership and ERCs.

Warfield et al. (1995) also document that discretionary accruals are lower when managerial ownership is high. Discretionary accruals are often indicative of biased reporting. ${ }^{16}$ Warfield et al. (1995) interpret this finding as evidence of higher managerial ownership leading to less reporting bias, which they attribute to their finding of a positive association between managerial ownership and ERCs.

Within the framework of our model, expected bias may be lower with higher managerial ownership if higher managerial ownership is correlated with other factors that influence the reporting environment. For instance, the Board of Directors may recognize higher managerial

15 In our model, $\tau$ is characterized as the manager's share of firm value. As managerial ownership increases, the benefit to the manager increases. The influence of the manager over the firm's operations is also likely to increase as managerial ownership increases. Thus with higher levels of ownership, the manager can override internal controls or governance mechanisms more easily, characterized in our model as a lower cost $q$ of bias. Other examples of managerial incentives that could affect both the costs and benefits of biased reporting include stock options (see Aboody 1996) and managerial ability (see Demerjian, Lev, and McVay 2012; Demerjian, Lev, Lewis, and McVay 2013). In these examples, $q$ increases because of the risk of stock option forfeiture or loss of managerial reputation. An increase in $\tau$ also results because the manager can increase the options value and protect his reputation through biased reporting.

16 Discretionary accruals are an imperfect proxy for reporting bias. For instance, neither the Jones nor the modified Jones discretionary accruals models (Dechow, Sloan, and Sweeney 1995) would identify all forms of biased reporting. Other proxies for biased reporting, such as accounting restatements or the mapping of accruals and cash flows (Dechow and Dichev 2002), are more likely to identify these other forms of biased reporting. 
ownership as a fraud risk factor and respond (through the audit committee) by selecting an auditor from a big-N audit firm and/or an audit firm specializing in their particular industry. A big-N auditor or an industry specialist faces a higher liability cost $L$, as well as reduced audit costs $k$ due to a more efficient auditing technology. ${ }^{17}$

If higher managerial ownership is correlated with the selection of a big-N auditor or industry specialist, our framework predicts that higher managerial ownership may result in a decrease in reporting bias. But an increase in managerial ownership also increases $\tau$ and likely decreases $q$, which our framework predicts may result in an increase in reporting bias. Therefore, whether we observe more or less reporting bias with higher managerial ownership depends on whether the downward pressure from changes in $k$ and $L$ are greater than the upward pressure from changes in $\tau$ and $q$. Warfield et al.'s (1995) results suggest that $k$ and $L$ dominate. However, regardless of the relative strengths from changes in $L$ and $k$ versus $\tau$ and $q$ and the resulting effects on expected bias, our results predict that managerial ownership is always positively associated with ERCs.

Warfield et al.'s (1995) study focuses on a single corporate governance choice that is associated with financial reporting. More recent corporate governance studies focus on choices that decrease the manager's incentive for biased reporting. For instance, Krishnan and Visvanathan (2008) and Dhaliwal, Naiker, and Navissi (2010) provide evidence that reporting bias (measured as accounting conservatism and accruals quality, respectively) is lower when the board chooses an accounting expert to serve on the audit committee.

17 Consistent with our characterization of a big-N audit firm as exhibiting higher audit quality (higher $L$, lower $k$ ), Teoh and Wong (1993) document that ERCs are higher for big-N audit firms than for non-big-N audit firms. 
The premise of Krishnan and Visvanathan (2008) and Dhaliwal et al. (2010) is that the oversight of management is higher when an accounting expert serves on the audit committee. Within our framework, the increase in the oversight of management increases the cost of biased reporting (higher $q$ ) and results in less reporting bias. Both Krishnan and Visvanathan (2008) and Dhaliwal et al.'s (2010) results are consistent with this prediction.

The audit committee is also charged with the hiring of the external auditor, among other responsibilities (see SOX, Section 301). The auditing literature suggests that audit committees with an accounting expert are more likely to hire a big-N auditor and/or an auditor specializing in the firm's industry (for a discussion, see DeFond and Zhang 2014). Within our framework, a big-N auditor or industry specialist (lower $k$, higher $L$ ) also results in less reporting bias. Therefore, the observed decrease in biased reporting when an accounting expert serves on the audit committee could result from either the committee's increased oversight of management or the committee's selection of auditors.

While the effect on reporting bias is the same under either scenario, our framework predicts that increased oversight would induce lower audit quality, but the choice of a big-N auditor or industry specialist would induce higher audit quality. Therefore, whether we observe higher or lower ERCs when an accounting expert serves on the audit committee depends on whether the upward effects on audit quality from changes in $k$ and $L$ are greater than the downward effects from changes in $q$. Again, this is because the association between expected audit quality and ERCs is always positive.

Neither Krishnan and Visvanathan (2008) nor Dhaliwal et al. (2010) consider how ERCs vary when an accounting expert serves on the audit committee. This relation is tested in Bryan, Liu, Tiras, and Zhuang (2013) who find that the positive association between audit committees 
and ERCs is stronger when the committee includes an accounting expert, suggesting that the changes in $k$ and $L$ dominate. However, Bryan et al. (2013) find this result to hold only when the selection of an accounting expert aligns with key firm characteristics. ${ }^{18}$ For those audit committees with an accounting expert that do not align with key firm characteristics, Bryan et al.'s (2013) lack of findings could result from these audit committees being less likely to select a big-N auditor or industry specialist, or from the effects of $k$ and $L$ on audit quality not dominating the effects from a higher $q$.

\section{Concluding remarks}

The discussion above highlights the importance of answering DeFond and Zhang's (2014) call for conceptual guidance to disentangle the relation between audit quality and the manager's reporting strategy. Without the benefit of this conceptual guidance, early ERC research, such as Warfield et al. (1995), have led empirical researchers to simply presume that the association between reporting bias and ERCs is negative. As such, more recent studies on reporting bias limit their focus to examining whether differences in managerial incentives affect specific earnings characteristics (i.e., accruals quality, conservatism, among others) that proxy for reporting bias (for a review, see Dechow et al. 2010).

Within the framework of our study, the presumed negative association between expected reporting bias and ERCs may occur when managerial incentives are correlated with the choice of auditor or other changes in a firm's reporting environment. However, if changes in the manager's incentives are not correlated with the board's corporate governance choices, or other reporting incentives, our framework predicts a positive association between expected reporting

18 In the post-SOX era, both the NYSE and NASDAQ require listed companies to include a financial expert on the audit committee. A firm's Board of Directors may choose a financial expert who is also an accounting expert. 
bias and ERCs. To date, the empirical literature has yet to consider these possibilities. For instance, Bryan et al. (2013) did not consider whether ERCs vary when audited by a big-N or non-big-N auditor and when the selection of an accounting expert on the audit committee aligns with key firm characteristics.

Our framework provides conceptual guidance for future empirical studies to disentangle whether the dominant effects of including an accounting expert on the audit committee, or other changes to a firm's corporate governance, is an improvement to the oversight of management or an improvement in the selection of auditors. This distinction is important not only to accounting researchers, but also to regulators, as they consider increasing the requirements placed on audit committees and expanding the audit committee's responsibilities. Our framework suggests that future research could address the usefulness of any proposed changes by examining whether they would lead to improvements in the audit committee's auditor selection process. 


\section{Appendix}

TABLE 1

Summary of notation

\begin{tabular}{|c|c|}
\hline \multicolumn{2}{|c|}{ Stochastic variables: } \\
\hline$\pi$ & True earnings - observed privately by the manager \\
\hline$\mu_{\pi}$ & Expected earnings - common knowledge \\
\hline$\sigma_{\pi}^{2}$ & Variance of earnings - common knowledge \\
\hline$\varepsilon$ & Manager's insensitivity to bias - observed privately by the manager \\
\hline$\mu_{\varepsilon}$ & Expected manager insensitivity to bias - common knowledge \\
\hline$\sigma_{\varepsilon}^{2}$ & Variance of the manager's insensitivity to bias - common knowledge \\
\hline$\gamma$ & $\begin{array}{l}\text { Relative measure of uncertainty about earnings and the manager's private } \\
\text { incentives for reporting bias: equal to } \sigma_{\pi}^{2} /\left(\sigma_{\pi}^{2}+\sigma_{\varepsilon}^{2}\right)\end{array}$ \\
\hline \multicolumn{2}{|c|}{ Payoff parameters (all common knowledge): } \\
\hline$q$ & Manager's cost of bias parameter \\
\hline$\tau$ & Manager's benefit parameter relative to the market price of the firm \\
\hline$k$ & Auditor's cost parameter that determines the direct cost of audit quality \\
\hline$L$ & Auditor's liability parameter for undetected bias \\
\hline \multicolumn{2}{|c|}{ Manager's strategy: } \\
\hline$r$ & $\begin{array}{l}\text { The manager's linear report based on true earnings and the manager's } \\
\text { insensitivity to bias: } r=b_{m} \pi+c_{m} \varepsilon+a_{m}\end{array}$ \\
\hline$a_{m}$ & The intercept of reported earnings \\
\hline$b_{m}$ & The weight given to true earnings in reported earnings \\
\hline$c_{m}$ & The weight given to the manager's insensitivity to bias in reported earnings \\
\hline \multicolumn{2}{|c|}{ Auditor's strategy: } \\
\hline$\delta$ & $\begin{array}{l}\text { The auditor's choice of audit quality based upon the manager's reported } \\
\text { earnings: } \delta=b_{A} r+a_{A}\end{array}$ \\
\hline$a_{A}$ & The intercept of the audit quality choice \\
\hline$b_{A}$ & The weight given to reported earnings in the auditor's audit quality choice \\
\hline \multicolumn{2}{|c|}{ Market response to reported earnings: } \\
\hline$P_{N D}$ & The market price if the auditor does not detect bias: $P_{N D}=\beta r+\alpha$ \\
\hline$\alpha$ & The intercept of $P_{N D}$ \\
\hline$\beta$ & The market's response to reported earnings in $P_{N D}$ \\
\hline$P_{D}$ & The market price if the auditor detects bias: $P_{D}=\pi$ \\
\hline \multicolumn{2}{|c|}{ Expected amounts of bias and audit quality (detection probability): } \\
\hline$E($ bias $)$ & Expected reporting bias \\
\hline$E(\delta)$ & Expected audit quality \\
\hline
\end{tabular}




\section{Proof of Lemma 1.}

We start by assuming that the manager's reporting strategy is linear in $\pi$ and $\varepsilon$ and then show that it is linear in equilibrium.

Let $r=b_{m} \pi+c_{m} \varepsilon+a_{m}$ where $b_{m}, c_{m}$ and $a_{m}$ are the manager's strategic choices in the reporting strategy $r$. Given, $r$ and $\pi$ are both normally distributed, we know that

$$
\begin{aligned}
& P_{N D}=E(\pi \mid r)=\mu_{\pi}+\frac{\operatorname{Cov}(\pi, r)}{\operatorname{Var}(r)}(r-E(r)) \\
& =\frac{b_{m} \sigma_{\pi}^{2}}{b_{m}^{2} \sigma_{\pi}^{2}+c_{m}^{2} \sigma_{\varepsilon}^{2}} r+\left(\mu_{\pi}-\frac{b_{m} \sigma_{\pi}^{2}}{b_{m}^{2} \sigma_{\pi}^{2}+c_{m}^{2} \sigma_{\varepsilon}^{2}}\left(b_{m} \mu_{\pi}+c_{m} \mu_{\varepsilon}+a_{m}\right)\right) .
\end{aligned}
$$

Let $\gamma=\frac{\sigma_{\pi}^{2}}{\sigma_{\pi}^{2}+\sigma_{\varepsilon}^{2}}$. Then,

$P_{N D}=\beta r+\alpha$, where $\beta=\frac{\gamma b_{m}}{\gamma b_{m}^{2}+(1-\gamma) c_{m}^{2}}$ and $\alpha=\left(\mu_{\pi}-\frac{\gamma b_{m}}{\gamma b_{m}^{2}+(1-\gamma) c_{m}^{2}}\left(b_{m} \mu_{\pi}+c_{m} \mu_{\varepsilon}+a_{m}\right)\right) \Rightarrow$ $\alpha=(1-\beta) \mu_{\pi}-\beta E($ bias $)$.

From (2) we have

$$
\begin{aligned}
& M=\tau(\beta r+\alpha)(1-\delta)+\tau \pi \delta-\frac{q}{2}(r-\pi-\varepsilon)^{2} \text { and thus with fixed } \delta, \\
& \frac{d M}{d r}=\tau \beta(1-\delta)-q(r-\pi-\varepsilon) .
\end{aligned}
$$

Setting the above equal to zero and solving for $r$, we find that

$$
r=\pi+\varepsilon+\frac{\tau \beta(1-\delta)}{q}
$$

Thus, $b_{m}=1$ and $c_{m}=1$, which implies that $\beta=\frac{\gamma b_{m}}{\gamma b_{m}^{2}+(1-\gamma) c_{m}^{2}}=\gamma$, and $r=\pi+\varepsilon+\frac{\tau \gamma(1-\delta)}{q}$.

Note also that bias $=r-\pi=\varepsilon+\frac{\tau \gamma(1-\delta)}{q}, E($ bias $)=\mu_{\varepsilon}+\frac{\tau \gamma(1-\delta)}{q}$ and $\alpha=(1-\gamma) \mu_{\pi}-\gamma\left(\mu_{\varepsilon}+\frac{\tau \gamma(1-\delta)}{q}\right)$ 


\section{Proof of Proposition 1.}

Next assume that $\delta=b_{A} r+a_{A}$ (which we will show is true in equilibrium).

From expression (2) we have

$\frac{d M}{d r}=-r\left(q+2 b_{A} \beta \tau\right)+\left(q+b_{A} \tau\right) \pi+q \varepsilon+\left(\left(1-a_{A}\right) \beta-b_{A} \alpha\right) \tau$

Note that $\frac{d^{2} M}{d r^{2}}<0$, so that the solution to $\frac{d M}{d r}=0$ gives us the manager's maximizing choice.

When we set $\frac{d M}{d r}=0$, we obtain $r=\frac{\left(q+b_{A} \tau\right) \pi+q \varepsilon+\left(\left(1-a_{A}\right) \beta-b_{A} \alpha\right) \tau}{\left(q+2 b_{A} \beta \tau\right)}$

Thus, $b_{m}=\frac{q+b_{A} \tau}{q+2 b_{A} \beta \tau}, c_{m}=\frac{q}{q+2 b_{A} \beta \tau}$ and $a_{m}=\frac{\left(\left(1-a_{A}\right) \beta-b_{A} \alpha\right) \tau}{q+2 b_{A} \beta \tau}$.

From Lemma 1, we have $P_{N D}=E(\pi \mid r)=\beta r+\alpha$, where $\beta=\frac{\gamma b_{m}}{\gamma b_{m}^{2}+(1-\gamma) c_{m}^{2}}$ and

$\alpha=\mu_{\pi}-\beta E(r)$

Thus, $\beta=\frac{\frac{q+b_{A} \tau}{q+2 b_{A} \beta \tau} \gamma}{\left(\frac{q+b_{A} \tau}{q+2 b_{A} \beta \tau}\right)^{2} \gamma+\left(\frac{q}{q+2 b_{A} \beta \tau}\right)^{2}(1-\gamma)}=\frac{\left(q+b_{A} \tau\right)\left(q+2 b_{A} \beta \tau\right) \gamma}{\left(q+b_{A} \tau\right)^{2} \gamma+q^{2}(1-\gamma)} \Rightarrow$

$\beta=\frac{q \gamma\left(q+b_{A} \tau\right)}{q^{2}-b_{A}^{2} \gamma \tau^{2}}$

In addition, $\alpha=(1-\beta) \mu_{\pi}-\beta E($ bias $)$, where $E($ bias $)=E(r)-\mu_{\pi}$.

Next, note from (4) that

$\frac{d A}{d \delta}=-L(r-E(\pi \mid r))+k \delta$. 
Setting (A1) $=0$, we get $\delta=\frac{L}{k}(r-E(\pi \mid r))$.

Also from (A1) we find that $\frac{d^{2} A}{d \delta^{2}}>0$ so that the solution for $\delta$ minimizes the auditor's expected costs.

Thus, $\delta=\frac{L}{k}(r-E(\pi \mid r))=\frac{L}{k}(r-\beta r-\alpha)=\frac{L}{k}((1-\beta) r-\alpha)$

$$
=b_{A} r+a_{A} \text { where } b_{A}=\frac{L}{k}\left(1-\frac{q \gamma\left(q+b_{A} \tau\right)}{q^{2}-b_{A}^{2} \gamma \tau^{2}}\right) \text { and } a_{A}=-\frac{L}{k}\left((1-\beta) \mu_{\pi}-\beta E(\text { bias })\right) \text {. }
$$

Note that based on the above results, $\alpha=-\frac{k}{L} a_{A}$ and

$$
a_{m}=\frac{\left(\left(1-a_{A}\right) \beta-b_{A} \alpha\right) \tau}{q+2 b_{A} \beta \tau}=\frac{\left(a_{A}(1-2 \beta)+\beta\right) \tau}{q+2 b_{A} \beta \tau}
$$

Proof that $E($ bias $)=\frac{k\left(q \mu_{\varepsilon}+\beta \tau\right)}{k q+L \beta \tau}$.

Consequently, because $E($ bias $)=E\left[r-\mu_{\pi}\right]=E[r]-\mu_{\pi}$, we have

$$
\begin{aligned}
& E(\text { bias })=\frac{q+b_{A} \tau}{q+2 b_{A} \beta \tau} \mu_{\pi}+\frac{q}{q+2 b_{A} \beta \tau} \mu_{\varepsilon}+\frac{\left(\frac{L}{k}\left(-(1-\beta) \mu_{\pi}+\beta E(\text { bias })\right)(1-2 \beta)+\beta\right) \tau}{q+2 b_{A} \beta \tau}-\mu_{\pi} \\
& =\frac{1}{q+2 b_{A} \beta \tau}\left\{\left(q+b_{A} \tau\right) \mu_{\pi}+q \mu_{\varepsilon}+\left(\frac{L}{k}\left(-(1-\beta) \mu_{\pi}+\beta E(\text { bias })\right)(1-2 \beta)+\beta\right) \tau-\left(q+2 b_{A} \beta \tau\right) \mu_{\pi}\right\} \\
& =\frac{1}{q+2 b_{A} \beta \tau}\left\{b_{A} \tau(1-2 \beta) \mu_{\pi}+q \mu_{\varepsilon}+\left(\frac{L}{k}\left(-(1-\beta) \mu_{\pi}+\beta E(\text { bias })\right)(1-2 \beta)+\beta\right) \tau\right\} \\
& =\frac{1}{q+2 \frac{L}{k}(1-\beta) \beta \tau}\left\{\frac{L}{k}(1-\beta) \tau(1-2 \beta) \mu_{\pi}+q \mu_{\varepsilon}+\left(\frac{L}{k}\left(-(1-\beta) \mu_{\pi}+\beta E(\text { bias })\right)(1-2 \beta)+\beta\right) \tau\right\}
\end{aligned}
$$




$$
\begin{aligned}
& =\frac{1}{k q+2 L(1-\beta) \beta \tau}\left\{k q \mu_{\varepsilon}+L \beta E(\text { bias })(1-2 \beta) \tau+k \beta \tau\right\} \Rightarrow \\
& E(\text { bias })(k q+2 L(1-\beta) \beta \tau-L \beta(1-2 \beta) \tau)=k q \mu_{\varepsilon}+k \beta \tau \Rightarrow \\
& \{E(\text { bias })\}(k q+L \beta \tau)=k q \mu_{\varepsilon}+k \beta \tau \Rightarrow \\
& E(\text { bias })=\frac{k\left(q \mu_{\varepsilon}+\beta \tau\right)}{k q+L \beta \tau} .
\end{aligned}
$$

Thus, $\alpha=(1-\beta) \mu_{\pi}-\beta \frac{k\left(q \mu_{\varepsilon}+\beta \tau\right)}{k q+L \beta \tau}$ and $a_{A}=-\frac{L}{k}\left((1-\beta) \mu_{\pi}-\beta \frac{k\left(q \mu_{\varepsilon}+\beta \tau\right)}{k q+L \beta \tau}\right)$.

$$
\begin{aligned}
& \text { Proof that } E(\delta)=\frac{L\left(q \mu_{\varepsilon}+\beta \tau\right)}{k q+L \beta \tau} \\
& a_{A}=-\frac{L}{k}\left((1-\beta) \mu_{\pi}-\beta E(\text { bias })\right) \\
& \Rightarrow \delta=b_{A} r-\frac{L}{k}\left((1-\beta) \mu_{\pi}-\beta E(\text { bias })\right)=b_{A} r-\frac{L}{k}\left((1-\beta)\left(\mu_{\pi}+E(\text { bias })\right)-E(\text { bias })\right) \\
& =b_{A}\left(r-\left(\mu_{\pi}+E(\text { bias })\right)\right)+\frac{L}{k}(E(\text { bias }))=b_{A}(r-E(r))+E(\delta) \\
& \Rightarrow E(\delta)=\frac{L\left(q \mu_{\varepsilon}+\beta \tau\right)}{k q+L \beta \tau} .
\end{aligned}
$$

Proof of the uniqueness of $\beta$ and $b_{A}$.

Note that if $b_{A}$ is unique, then it follows that $\beta$ is unique.

From Proposition 1 we know that 
$b_{A}=\frac{L}{k}\left(1-\frac{q \gamma\left(q+b_{A} \tau\right)}{q^{2}-b_{A}^{2} \gamma \tau^{2}}\right)$

Let $H b_{A}=b_{A}-\frac{L}{k}\left(1-\frac{q \gamma\left(q+b_{A} \tau\right)}{q^{2}-b_{A}^{2} \gamma \tau^{2}}\right)$.

Then, using implicit differentiation we get

$$
\frac{d b_{A}}{d \gamma}=-\frac{\frac{d H b_{A}}{d \gamma}}{\frac{d H b_{A}}{d b_{A}}}=-\frac{L q^{3}\left(q+b_{A} \tau\right)}{k\left(q^{2}-b_{A}^{2} \gamma \tau^{2}\right)^{2}+L q \gamma \tau\left(q^{2}+2 b_{A} q \gamma+b_{A}^{2} \gamma \tau^{2}\right)}<0 \text { as long as } b_{\mathrm{A}}>0 .
$$

The solution for $b_{A}$ in expression (A2) is a root to a cubic polynomial (there are three of them) but we only want the root that is finite, real, and corresponds to $\beta>0, b_{A}>0$. Now $\gamma \in[0,1]$ based on its definition.

Suppose $\gamma=0$, then there is a unique solution of $b_{A}=\frac{L}{k}$. We require that $b_{A}<\frac{L}{k}$ because $b_{A}=\frac{L}{k}(1-\beta)$ and we also require that $\beta>0$.

Let $\gamma=1$, then there are two solutions of $b_{A}=0$ or $b_{A}=\frac{k q+L \tau}{k \tau}$.

Now because $\frac{d b_{A}}{d \gamma}<0$ at $b_{A}=\frac{L}{k}>0$ with $\gamma=0$ and $\frac{k q+L \tau}{k \tau}=\frac{q}{\tau}+\frac{L}{k}>\frac{L}{k}$, the solution at $\gamma=1$ must be $b_{A}=0$. (If $b_{A}=\frac{k q+L \tau}{k \tau}$, then $\beta<0$ for $\gamma \leq 1$, which contradicts $\beta>0$ ).

Thus, $0<b_{A}<\frac{L}{k}$ and $0<\beta<1$ with $\beta=1$ at $\gamma=1$ and $\beta=0$ with $\gamma=0$.

\section{Proof of Corollary 2.}

Based on Expression (5), Lemma 1 and Proposition $1, \beta=\gamma$ when $b_{A}=0$.

Moreover, using $\beta$ as defined in Proposition $1, \frac{d \beta}{d b_{A}}=\frac{q \gamma \tau\left(q^{2}+2 b q \gamma \tau+b^{2} \gamma \tau^{2}\right)}{\left(q^{2}-b^{2} \gamma \tau^{2}\right)^{2}}>0$.

\section{Proof of Proposition 2.}

Proof that $\frac{d b_{A}}{d q}>0$ and $\frac{d \beta}{d q}<0$. 
Let $H b_{A}=b_{A}-\frac{L}{k}\left(1-\frac{q \gamma\left(q+b_{A} \tau\right)}{q^{2}-b_{A}^{2} \gamma \tau^{2}}\right)$

Thus, $\frac{d b_{A}}{d q}=-\frac{\frac{d H b_{A}}{d q}}{\frac{d H b_{A}}{d b_{A}}}=\frac{b_{A} L \gamma \tau\left(q^{2}+2 b_{A} q \gamma \tau+b_{A}^{2} \gamma \tau^{2}\right)}{k\left(q^{2}-b_{A}^{2} \gamma \tau^{2}\right)^{2}+L q \gamma \tau\left(q^{2}+2 b_{A} q \gamma \tau+b_{A}^{2} \gamma \tau^{2}\right)}>0$.

Also, $\beta=\frac{q \gamma\left(q+b_{A} \tau\right)}{q^{2}-b_{A}^{2} \gamma \tau^{2}}$ and $\frac{d \beta}{d q}=\frac{\gamma \tau\left(q^{2}+2 q \gamma \tau b_{A}[q]+\gamma \tau^{2} b_{A}[q]^{2}\right)\left(-b_{A}[q]+q b_{A}^{\prime}[q]\right)}{\left(q^{2}-\gamma \tau^{2} b_{A}[q]^{2}\right)^{2}}<0$

because

$$
\begin{aligned}
& \left(b_{A}[q]-q b_{A}^{\prime}[q]\right)=b_{A}\left(1-\frac{q L \gamma \tau\left(q^{2}+2 b_{A} q \gamma \tau+b_{A}{ }^{2} \gamma \tau^{2}\right)}{k\left(q^{2}-b_{A}{ }^{2} \gamma \tau^{2}\right)^{2}+q L \gamma \tau\left(q^{2}+2 b_{A} q \gamma \tau+b_{A}{ }^{2} \gamma \tau^{2}\right)}\right)>0 . \\
& \text { Also note that } \frac{d\left(\frac{q}{q+b_{A}[q] \tau}\right)}{d q}=\frac{\tau\left(b_{A}[q]-q b_{A}^{\prime}[q]\right)}{\left(q+\tau b_{A}[q]\right)^{2}}>0 .
\end{aligned}
$$

Thus the increase in the ratio $\frac{q}{q+b_{A}[q] \tau}$ due to an increase in $q$, is the main driver of the corresponding decrease in $\beta$ based on Expression (5).

Proof that $\frac{d b_{A}}{d \tau}<0$ and $\frac{d \beta}{d \tau}>0$.

$$
\begin{aligned}
& \frac{d b_{A}}{d \tau}=-\frac{\frac{d H b_{A}}{d \tau}}{\frac{d H b_{A}}{d b_{A}}}=-\frac{b_{A} L q \gamma\left(q^{2}+2 b_{A} q \gamma \tau+b_{A}{ }^{2} \gamma \tau^{2}\right)}{k\left(q^{2}-b_{A}{ }^{2} \gamma \tau^{2}\right)^{2}+L q \gamma \tau\left(q^{2}+2 b_{A} q \gamma \tau+b_{A}{ }^{2} \gamma \tau^{2}\right)}<0 \text { and } \\
& \frac{d \beta}{d \tau}=\frac{q \gamma\left(q^{2}+2 q \gamma \tau b_{A}[\tau]+\gamma \tau^{2} b[\tau]^{2}\right)\left(b_{A}[\tau]+\tau b_{A}^{\prime}[\tau]\right)}{\left(q^{2}-\gamma \tau^{2} b_{A}[\tau]^{2}\right)^{2}}>0, \text { where } \\
& \left(b_{A}[\tau]+\tau b_{A}^{\prime}[\tau]\right)=b_{A}\left(1-\frac{L q \gamma \tau\left(q^{2}+2 b_{A} q \gamma \tau+b_{A}{ }^{2} \gamma \tau^{2}\right)}{k\left(q^{2}-b_{A}{ }^{2} \gamma \tau^{2}\right)^{2}+L q \gamma \tau\left(q^{2}+2 b_{A} q \gamma \tau+b_{A}{ }^{2} \gamma \tau^{2}\right)}\right)>0 .
\end{aligned}
$$


Thus, $\beta$ decreases in $q$ (increases in $\tau$ ) while $b_{A}$ increases in $q$ (decreases in $\tau$ ).

Recall that $E(\delta)=\frac{L\left(q \mu_{\varepsilon}+\beta \tau\right)}{k q+L \beta \tau}=\frac{L}{k} E($ bias $)$.

Therefore,

$\frac{d E(\text { bias })}{d q}=\frac{k\left(k-L \mu_{\varepsilon}\right) \tau\left(-\beta[q]+q \beta^{\prime}[q]\right)}{(k q+L \tau \beta[q])^{2}}<0$ because $\beta^{\prime}[q]<0$ and $\left(k-L \mu_{\varepsilon}\right)>0$ by

assumption. As a result, $\frac{d E(\delta)}{d q}=\frac{L}{k} \frac{d E(\text { bias })}{d q}<0$.

Similarly, $\frac{d E(\text { bias })}{d \tau}=\frac{k q\left(k-L \mu_{\varepsilon}\right)\left(\beta[\tau]+\tau \beta^{\prime}[\tau]\right)}{(k q+L \tau \beta[\tau])^{2}}>0$ and $\frac{d E(\delta)}{d \tau}=\frac{L}{k} \frac{d E(\text { bias })}{d \tau}>0$.

Proof that $\frac{d b_{A}}{d L}>0, \frac{d \beta}{d L}>0, \frac{d b_{A}}{d k}<0$ and $\frac{d \beta}{d k}<0$.

$\frac{d b_{A}}{d L}=-\frac{\frac{d H b_{A}}{d L}}{\frac{d H b_{A}}{d b_{A}}}=\frac{k}{L} \frac{b_{A}\left(q^{2}-b_{A}^{2} \gamma \tau^{2}\right)^{2}}{k\left(q^{2}-b_{A}^{2} \gamma \tau^{2}\right)^{2}+L q \gamma \tau\left(q^{2}+2 b_{A} q \gamma \tau+b_{A}^{2} \gamma \tau^{2}\right)}>0$ and

$\frac{d \beta}{d L}=\frac{q \gamma \tau\left(q^{2}+2 q \gamma \tau b_{A}[L]+\gamma \tau^{2}\left(b_{A}[L]\right)^{2}\right) b_{A}^{\prime}[L]}{\left(q^{2}-\gamma \tau^{2}\left(b_{A}[L]\right)^{2}\right)^{2}}>0$

Similarly, $\frac{d b_{A}}{d k}=-\frac{\frac{d H b_{A}}{d k}}{\frac{d H b_{A}}{d b_{A}}}=-\frac{b_{A}\left(q^{2}-b_{A}^{2} \gamma \tau^{2}\right)^{2}}{k\left(q^{2}-b_{A}^{2} \gamma \tau^{2}\right)^{2}+L q \gamma \tau\left(q^{2}+2 b_{A} q \gamma \tau+b_{A}^{2} \gamma \tau^{2}\right)}<0$ and

$\frac{d \beta}{d k}=\frac{q \gamma \tau\left(q^{2}+2 q \gamma \tau b_{A}[k]+\gamma \tau^{2}\left(b_{A}[k]\right)^{2}\right) b_{A}^{\prime}[k]}{\left(q^{2}-\gamma \tau^{2}\left(b_{A}[k]\right)^{2}\right)^{2}}<0$. 
Note that based on the results presented above that $\frac{d b_{A}}{d L}=-\frac{k}{L} \frac{d b_{A}}{d k}$ and $\frac{d \beta}{d L}=-\frac{k}{L} \frac{d \beta}{d k}$.

Proof that $\frac{d E(\delta)}{d L}>0, \frac{d E(\delta)}{d k}<0, \frac{d E(\text { bias })}{d L}<0$, and $\frac{d E(\text { bias })}{d k}>0$.

As before, we know that:

$$
\begin{aligned}
& E(\delta)=\frac{L\left(q \mu_{\varepsilon}+\beta \tau\right)}{k q+L \beta \tau}=\frac{L}{k} E(\text { bias }) ; \\
& \frac{d E(\delta)}{d L}=\frac{q\left(k q \mu_{\varepsilon}+k \tau \beta[L]+L\left(k-L \mu_{\varepsilon}\right) \tau \beta^{\prime}[L]\right)}{(k q+L \tau \beta[L])^{2}}>0 \text { because } L\left(k-L \mu_{\varepsilon}\right)>0 \text { and } \beta^{\prime}[L]>0 \\
& \frac{d E(\delta)}{d k}=-\frac{L q\left(q \mu_{\varepsilon}+\tau \beta[k]+\tau\left(-k+L \mu_{\varepsilon}\right) \beta^{\prime}[k]\right)}{(k q+L \tau \beta[k])^{2}}<0 \text { because } L\left(k-L \mu_{\varepsilon}\right)>0 \text { and } \beta^{\prime}[k]<0 .
\end{aligned}
$$

Next, consider $E($ bias $)$ :

$$
\frac{d E(\text { bias })}{d L}=-\frac{k \tau\left(q \mu_{\varepsilon} \beta[L]+\tau \beta[L]^{2}+q\left(-k+L \mu_{\varepsilon}\right) \beta^{\prime}[L]\right)}{(k q+L \tau \beta[L])^{2}}<0,
$$

because, as we have shown above, $\beta^{\prime}[L]=-\frac{k}{L} \beta^{\prime}[k]$ and we have assumed (see footnote 9) that $\frac{k}{L}>\mu_{\varepsilon}>\operatorname{Max}\left[0, \frac{-L \tau \beta^{2}-k^{2} q \beta^{\prime}[k]}{L q\left(\beta-k \beta^{\prime}[k]\right)}\right]$ where $\frac{-\tau \beta^{2}+k q \beta^{\prime}[L]}{q\left(\beta+L \beta^{\prime}[L]\right)}=\frac{-L \tau \beta^{2}-k^{2} q \beta^{\prime}[k]}{L q\left(\beta-k \beta^{\prime}[k]\right)}$. Note also that $\frac{-L \tau \beta^{2}-k^{2} q \beta^{\prime}[k]}{L q\left(\beta-k \beta^{\prime}[k]\right)}$ is independent of $\mu_{\varepsilon}$ because $\beta^{\prime}\left[\mu_{\varepsilon}\right]=0$. Likewise, $\frac{d E(\text { bias })}{d k}=\frac{\tau\left(L q \mu_{\varepsilon} \beta[k]+L \tau \beta[k]^{2}+k q\left(k-L \mu_{\varepsilon}\right) \beta^{\prime}[k]\right)}{(k q+L \tau \beta[k])^{2}}>0$, because, again, we have assumed that $\frac{k}{L}>\mu_{\varepsilon}>\operatorname{Max}\left[0, \frac{-L \tau \beta^{2}-k^{2} q \beta^{\prime}[k]}{L q\left(\beta-k \beta^{\prime}[k]\right)}\right]$. 
Furthermore, $\frac{-L \tau \beta^{2}-k^{2} q \beta^{\prime}[k]}{L q\left(\beta-k \beta^{\prime}[k]\right)}<0$ when $\gamma>1 / 2$ or $\sigma_{\pi}^{2}>\sigma_{\varepsilon}^{2}$ where relatively more is

known about the manager's type versus earnings. Thus, the assumption $\mu_{\varepsilon}>0$ suffices when

$\gamma>1 / 2$. A sufficiently large $\mu_{\varepsilon}$ is consistent with the manager's insensitivity to overstatement penalties.

Finally, note that $\frac{-L \tau \beta^{2}-k^{2} q \beta^{\prime}[k]}{L q\left(\beta-k \beta^{\prime}[k]\right)}<\frac{-k^{2} q \beta^{\prime}[k]}{L q\left(\beta-k \beta^{\prime}[k]\right)}=\frac{k}{L} \frac{-k q \beta^{\prime}[k]}{\beta q-k q \beta^{\prime}[k]}<\frac{k}{L}$. Thus, a $\mu_{\varepsilon}$ always exists such that $\frac{k}{L}>\mu_{\varepsilon}>\operatorname{Max}\left[0, \frac{-L \tau \beta^{2}-k^{2} q \beta^{\prime}[k]}{L q\left(\beta-k \beta^{\prime}[k]\right)}\right]$.

Proof of Proposition 3.

$\frac{d b_{A}}{d \gamma}=-\frac{\frac{d H b_{A}}{d \gamma}}{\frac{d H b_{A}}{d b_{A}}}=-\frac{L q^{3}\left(q+b_{A} \tau\right)}{k\left(q^{2}-b_{A}^{2} \gamma \tau^{2}\right)^{2}+L q \gamma \tau\left(q^{2}+2 b_{A} q \gamma+b_{A}^{2} \gamma \tau^{2}\right)}<0$.

Because $b_{A}=\frac{L}{k}(1-\beta), \beta=1-b_{A} \frac{k}{L}$. Thus, $\frac{d \beta}{d \gamma}=-\frac{d b_{A}}{d \gamma} \frac{k}{L}>0$.

Recall that $E(\delta)=\frac{L\left(q \mu_{\varepsilon}+\beta \tau\right)}{k q+L \beta \tau}=\frac{L}{k} E($ bias $)$.

Then, $\frac{d E(\text { bias })}{d \gamma}=\frac{k q\left(k-L \mu_{\varepsilon}\right) \tau \beta^{\prime}[\gamma]}{(k q+L \tau \beta[\gamma])^{2}}>0$ because $\beta^{\prime}[\gamma]>0$ and $k-L \mu_{\varepsilon}>0$, by assumption.

Similarly, $\frac{d E(\delta)}{d \gamma}=\frac{L}{k} \frac{d E(\text { bias })}{d \gamma}>0$. 


\section{References}

Aboody, D. 1996. Market valuation of employee stock options. Journal of Accounting and Economics 22 (1-3) 357-391.

American Institute of Certified Public Accountants (AICPA). 2012. The Consideration of Fraud in a Financial Statement Audit, SAS No. 122; No. 128. AU-C 240. New York: AICPA.

Beyer, A., and S. Sridhar. 2006. Effects of multiple clients on the reliability of audit reports. Journal of Accounting Research 44 (1): 29-51.

Bryan, D., C. Liu, S. Tiras, and Z. Zhuang. Optimal versus suboptimal choices of accounting expertise on audit committees and earnings quality. Review of Accounting Studies 18: 1123-1158.

Caskey, J., V. Nagar, and P. Petacchi. 2010. Reporting bias with an audit committee. The Accounting Review 85 (2): 447-481.

Chan, D., and S. Pae. 1998. An analysis of the economic consequences of the proportionate liability rule. Contemporary Accounting Research 15 (4): 457-480.

Dhaliwal, D., V. Naiker, and F. Navissi. 2010. The association between accruals quality and the characteristics of accounting experts and mix of expertise on audit committees.

Contemporary Accounting Research 27 (3): 787-827.

Dechow, P. and I. Dichev. 2002. The quality of accruals and earnings: The role of accrual estimation errors. The Accounting Review 77 (4): 35-59.

Dechow, P., W. Ge, and C. Schrand. 2010. Understanding earnings quality: A review of the proxies, their determinants and their consequences. Journal of Accounting and Economics $50(2-3) 344-401$

Dechow, P., R. Sloan, and A. Sweeney. 1995. Detecting earnings management. The Accounting Review 70 (2), 193-225.

DeFond, M. and J. Zhang. 2014. A review of archival auditing research. Journal of Accounting and Economics 58 (2-3): 275-326.

Demerjian, P., B. Lev, and S. McVay. 2012. Quantifying managerial ability: A new measure and validity tests. Management Science 58 (7): 1229-1248.

Demerjian, P., B. Lev, M. Lewis, and S. McVay. 2013. Managerial ability and earnings quality. The Accounting Review 88 (2): 463-498.

Dye, R., and S. Sridhar. 2004. Reliability-relevence trade-offs and the efficiency of aggregation. Journal of Accounting Research 42 (1): 51-88.

Fischer, P. and R. Verrecchia. 2000. Reporting bias. The Accounting Review 75 (2): 229-245. 
Hansen, S. 1993. Strategic sampling, physical units sampling, and dollar units sampling. The Accounting Review 68 (2): 323-345.

Hillegeist, S. 1999. Financial reporting and auditing under alternative damage apportionment rules. The Accounting Review 74 (3): 347-369.

Krishnan, G.V., and Visvanathan, G. 2008. Does the SOX definition of an accounting expert matter? The association between audit committee directors' accounting expertise and accounting conservatism. Contemporary Accounting Research 25 (3): 827-857.

Laux, V., and Newman, P. 2010. Auditor liability and client acceptance decisions. The Accounting Review 85 (1): 261-285.

Morrissey, J., Deputy Chief Accountant, U.S. Securities \& Exchange Commission. March 21, 2000. "Speech by SEC Staff: Corporate Responsibility and the Audit Committee."

Newman, P., and J. Noel. 1989. Error rates, detection rates, and payoff functions in auditing. Auditing: A Journal of Practice and Theory 8 (2): 50-63.

Newman, P., E. Patterson, and R. Smith. 2001. The influence of potentially fraudulent reports on audit risk assessment and planning. The Accounting Review 76 (1): 59-80.

Newman, P., E. Patterson, and R. Smith. 2005. The role of auditing in investor protection. The Accounting Review 80 (1): 289-313.

Newman, P., S. Rhoades, and R. Smith. 1996. Allocating audit resources to detect fraud. Review of Accounting Studies 1 (2): 161-182.

Patterson, E., and J. Noel. 2003. Audit strategies and multiple fraud opportunities of misreporting and defalcation. Contemporary Accounting Research 20 (3): 519-549.

Patterson, E., and R. Smith. 2003. Materiality uncertainty and earnings misstatement. The Accounting Review 78 (3): 819-846.

Public Company Accounting Oversight Board (PCAOB). 2002. Audit Evidence (AS 1105).

Public Company Accounting Oversight Board (PCAOB). 2002. Identifying and Assessing Risks of Material Misstatement (AS 2110).

Public Company Accounting Oversight Board (PCAOB). 2002. Consideration of Fraud in a Financial Statement Audit (AS 2401).

Radhakrishnan, S. 1999. Investors' recovery friction and auditor liability rules. The Accounting Review 74 (2): 225-240.

Sarbanes-Oxley Act of 2002 (SOX), 2002. Pub.L. 107-204.

Shibano, T. 1990. Assessing audit risk from errors and irregularities. Journal of Accounting Research 28 (Supplement): 110-140. 
Teoh, S.H. and T.J. Wong. 1993. Perceived auditor quality and the earnings response coefficient. The Accounting Review 68 (2): 346-367.

Warfield, T.D., J.J. Wild, and K.L. Wild. 1995. Managerial ownership, accounting choices, and informativeness of earnings. Journal of Accounting and Economics 20 (1): 61-92. 
Figure 1 The change in $\beta$ as $q$ increases for the case with strategic auditing $\left(b_{A}>0\right)$ compared to the benchmark case with constant auditing $\left(b_{A}=0\right)$

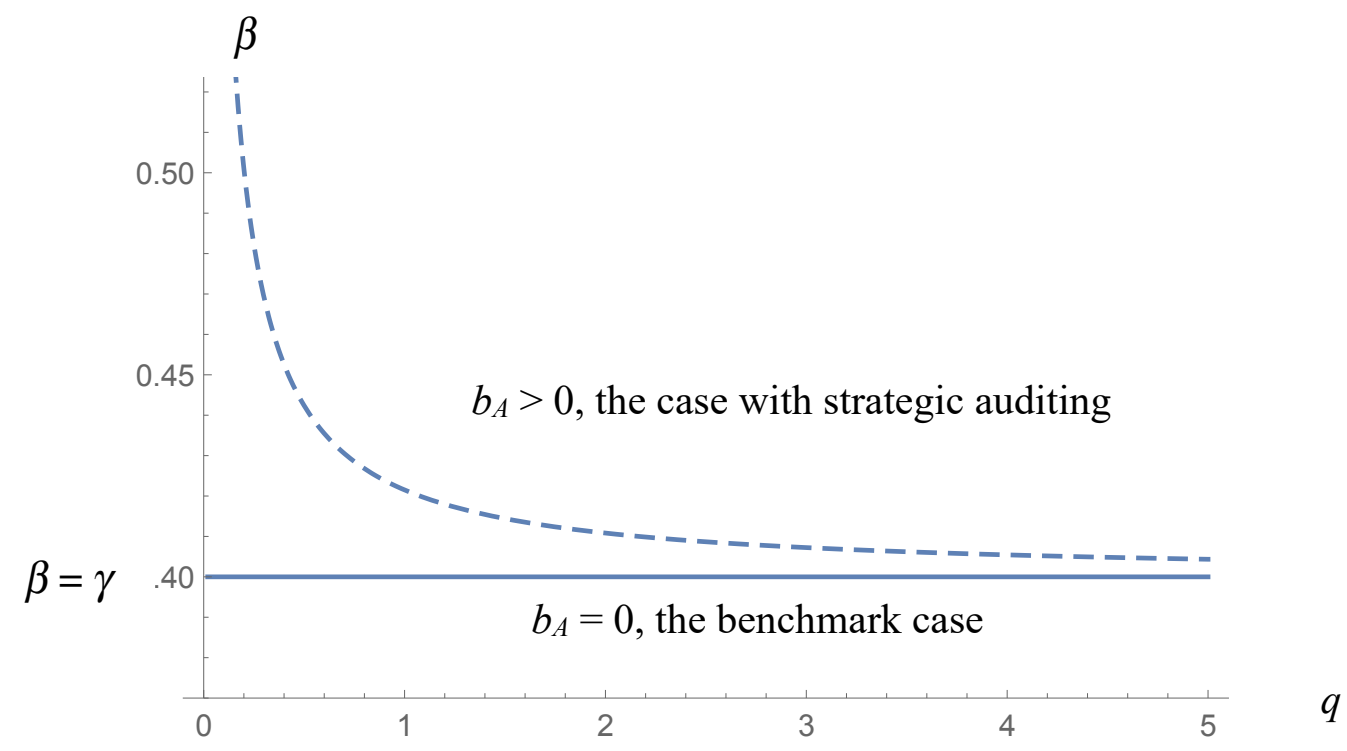


Figure 2 Empirical implications of changes in independent variables that proxy for the cost $(q)$ and benefit $(\tau)$ of biased reporting, the cost of auditing $(k)$, and the auditor's liability $(L)$ cost on financial reporting quality

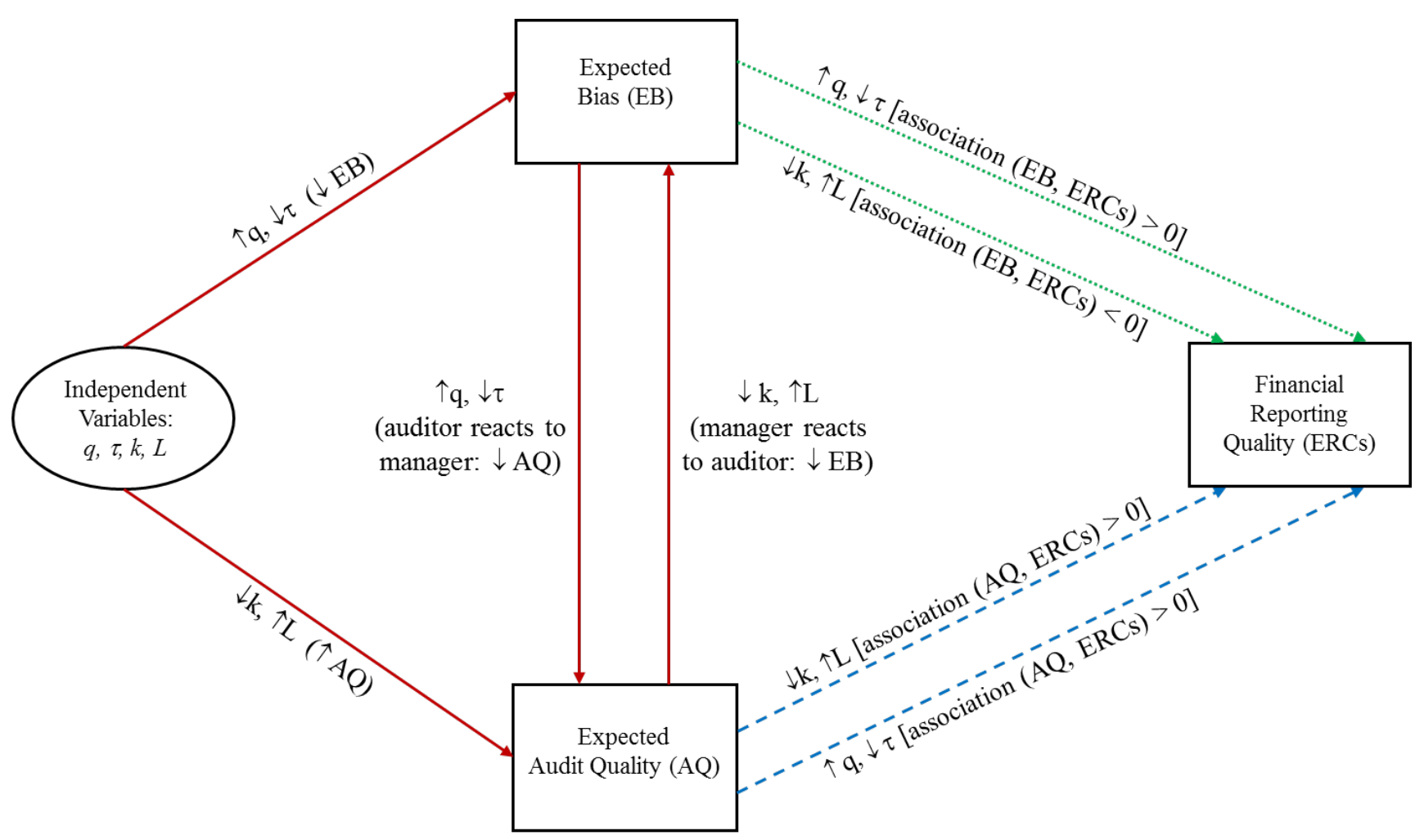

$\longrightarrow$ indicates a causal relation,

$---\rightarrow$ indicates association (AQ, ERCs) result from causal relation between independent variables $(q, \tau, k, L)$ and the expected probability of detection; and,

$\rightarrow$ indicates association (EB, ERCs) result from causal relation between independent variables $(q, \tau, k, L)$ and the expected probability of detection. 